\title{
Terephthalic acid derived ligand-stabilized palladium nanocomposite catalyst for Heck coupling reaction: without surface-modified heterogeneous catalyst
}

\author{
Jithendra kumara K. S. ${ }^{a}$, Krishnamurthy G. ${ }^{\text {a*, Kumara swamy B. E. }}$, \\ Shashi kumar N. D. ${ }^{a}$, Satish naik ${ }^{a}$, Krishna B. S. ${ }^{c}$ and Nagaraj naik ${ }^{d}$
}

A new protocol is reported for the synthesis of a heterogeneous palladium nanocomposite stabilized with a terephthalic acid-derived ligand ( $\mathrm{N}, \mathrm{N}$-bis(4-hydroxy-3-methoxybenzylidene)terephthalohydrazide). This is a highly insoluble ligand in common organic solvents, except dimethylformamide and dimethylsulfoxide. The resulting palladium nanocomposite acts as an efficient catalyst precursor for Mizoroki-Heck coupling reactions conducted under various reaction conditions. The spectral data suggest that the rate, yield and recycling of the catalyst are more effective for C-C coupling reactions. Copyright $\odot 2016$ John Wiley \& Sons, Ltd.

Additional supporting information may be found in the online version of this article at the publisher's web site.

Keywords: palladium nanocomposite; reverse micelle; heterogeneous catalyst; Heck reaction

\section{Introduction}

Ligand design plays a vital role in coordination chemistry allowing overall structural features to be exhibited at a macromolecular to nano-size level through ligand modification. ${ }^{[1]}$ Metal nanoparticles have attracted much attention as a result maximum effort being devoted to the development of nano-sized articles. The advantages of both nanocomposite and catalysis are a most interesting combination, in heterogeneous and homogeneous catalysis. Yet a number of questions remain, like morphology of the particles, controlling the shape and size, and available active surface of particles in solution. Concerning this question, recently an organometallic approach was developed. ${ }^{[1]}$ In the present scenario the development of new stabilizers enabling modification and control of the properties of palladium nanoparticles (size, surface structure and electronic properties) remains a challenge. ${ }^{[1]}$ The presence of coordinated ligands at their surface prevents the particles from coalescing and precipitating and allows their self-assembly on various surfaces. In the past few years, the coordination properties of various ligands on metal nanoparticles as stabilizers have been studied. ${ }^{[2-4]}$ Organic molecules such as amines, ${ }^{[5]}$ thiols ${ }^{[6,7]}$ and alcohols ${ }^{[8]}$ are used as stabilizers, among which the thiols are firmly fixed on the surface of ruthenium and platinum nanoparticles, ${ }^{[2-4]}$ in the same way as palladium nanoparticles with triphenylphosphine ${ }^{[9-11]}$ and trioctylphosphine ${ }^{[12-14]}$ which have weaker coordination ability. Recently palladium nanoparticles of specific size capped by phenanthroline have been reported. ${ }^{[15]}$ Gall et al. have studied pyridyl-substituted porphyrin ring used as a surface stabilizer in which the porphyrin ring completely wraps the metal nanoparticle and the nitrogen atom forms a stable bond with metal nanoparticles. ${ }^{[16]}$ Ramirez et al. have demonstrated the influence of organic ligands on the stabilization of palladium nanocomposite, and the protective effect of hexadecylamine depends on the amount of ligand added as well as the result of equilibrium present at the surface of the particles. ${ }^{[1]}$ Comparative studies of ligand coordination ability between metal nanoparticles and organometallic compounds would provide useful information for the catalytic applications of palladium nanoparticles. ${ }^{[17,18]}$ Bis-benzimidazolediamide derivatives as ligands provide nitrogen and carbonyl oxygen as donating sites and hence they have been extensively used in coordination and organometallic chemistry. ${ }^{[19]}$ These types of ligands are used for the synthesis of copper nanocomposites. A terephthalic acid (TPA)-derived ligand also shows structural and functional similarity to bis-benzimidazolediamide; hence in the work reported herein we used such a ligand as a stabilizer for the synthesis of a palladium nanocomposite using the reverse micelle method. This method was used to control the size of the palladium nanocomposite and increase the availability of active surface in solution for catalytic activity.

\footnotetext{
* Correspondence to: Krishnamurthy G., Department of Chemistry, Sahyadri Science College, Shimoga, Karnataka 577203, India. E-mail: gkmnaik_sahyadri@yahoo. co.in

a Department of Chemistry, Sahyadri Science College, Shimoga, Karnataka, India

b Department of Industrial Chemistry, Kuvempu University, Shimoga, Karnataka, India

c Department of Chemistry, Sapthagiri Institute of Technology, Bangaloru, Karnataka, India

d Department of Chemistry, University of Mysore, Mysore, Karnataka, India
} 
The Heck reaction ${ }^{[20-27]}$ involves the coupling of aryl, vinyl, benzyl or allyl halides with olefins in homogeneous or heterogeneous source of palladium as catalyst under basic conditions. ${ }^{[28-31]}$ Reactivity of Heck reactions varies on the basis of halogens, i.e. chlorine is less reactive when compared with bromine and bromine is less reactive than iodine under general conditions; ${ }^{[32-39]}$ however, chlorine gives good results with palladium catalysts with bulky phosphine ligands or carbenes. ${ }^{[40-43]}$ Aminopropyl-functionalized clay has been used as a support to prepare a palladium nanocatalyst for Heck ${ }^{[44]}$ and Suzuki cross-coupling reactions. ${ }^{[45]}$ Whereas a colloidal catalyst was not recycled quantitatively, with some exceptions on heterogeneous supports (such as silica, ${ }^{[46,47]}$ zeolites, ${ }^{[48]}$ carbon nanotubes, ${ }^{[49]}$ graphite oxide and graphene, ${ }^{[50]}$ polymers, ${ }^{[51]}$ metal-organic frameworks ${ }^{[52,53]}$ ), on the other hand, surface-modified palladium nanocomposites were used as heterogeneous catalysts wherein effective recovery of the catalyst was reported. ${ }^{[54-58]}$

A literature survey shows that there is no work related to polydentate ligand-stabilized palladium nanocomposites synthesized by the reverse micelle method and screening of their catalytic activity. Hence in this paper we present a detailed account of work leading to the optimization of the Heck reaction with respect to varying organic solvent, base, temperature and palladium nanocatalyst loading, and investigation of recycling of the catalyst.

\section{Materials and methods}

\section{General experiments}

TPA, hydrazine hydrate, vanillin, cetyltrimethylammonium bromide (CTAB), $n$-butanol, isooctane, allyl acetates, aryl halides, HPLC-grade chloroform, dichloromethane and palladium acetate were procured from Sigma-Aldrich (India), Himedia (India) and Lobo Chemicals (India) (commercially available from local sources) and were used as received without further purification. Freshly distilled solvents were employed for all synthetic purposes. Spectroscopicgrade solvents were employed for spectroscopic purposes. All other chemicals were of AR grade.

The progress of all coupling reactions was monitored by TLC. Yields refer to isolated yields after column chromatographic purification of compounds that have a purity of $\geq 95 \%$. The products of Heck reactions were authenticated by matching spectroscopic data of the products obtained by us with those reported in the literature.

${ }^{1} \mathrm{H}$ NMR and ${ }^{13} \mathrm{C}$ NMR spectra were recorded with a JNM-ECS-400 NMR spectrometer at 399.78 and $75.03 \mathrm{MHz}$, respectively, and a Bruker Avance III, $400 \mathrm{MHz}$, 9.4 T magnet, with chemical shifts reported in ppm relative to the residual deuterated solvent or the internal standard tetramethylsilane. Elemental analyses were carried out with a PerkinElmer 2400 Series II C, H, N analyser. UV-visible spectra were recorded with a Varian Cary 5000. Melting points were determined in an electrically heated apparatus by taking the sample in a glass capillary sealed at one end.

\section{Dimethylbenzene-1,4-dicarboxylate (1a; Scheme 1)}

TPA (1; $18.33 \mathrm{~g}, 0.05 \mathrm{~mol})$, methanol $(200 \mathrm{ml})$ and $\mathrm{H}_{2} \mathrm{SO}_{4}(5 \mathrm{ml})$ were heated under reflux for $4 \mathrm{~h}$. Solid $\mathrm{NaHCO}_{3}$ was added to neutralize the acid to $\mathrm{pH}=7$ and filtered off. The filtrate was evaporated to dryness under vacuum to give a white solid, which was recrystallized from ether-petroleum ether $\left(40-60^{\circ} \mathrm{C}\right)$ to afford colourless crystalline dimethylterephthalate $\mathbf{1 a}^{[59]}$ in $93 \%$ yield (19.25 g).

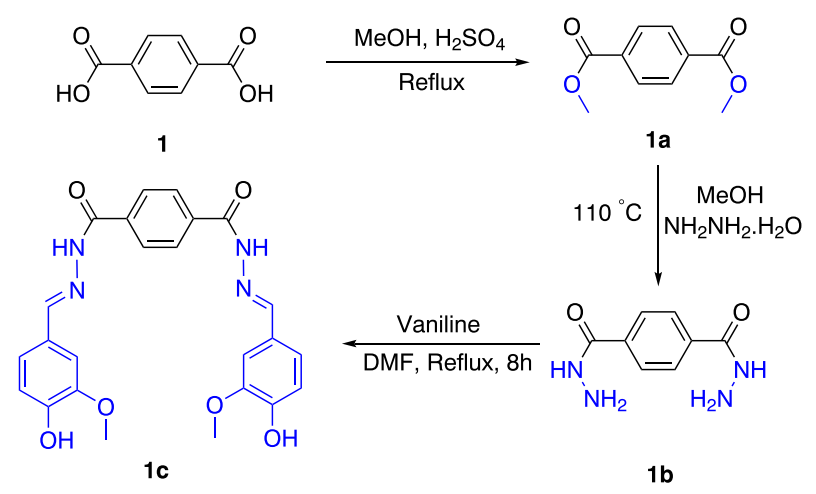

Scheme 1. Reagents and conditions for the synthesis of TPA ligand.

\section{Benzene-1,4-dicarbohydrazide (1b; Scheme 1)}

Dimethylterephthalate $(1 \mathrm{a} ; 6.00 \mathrm{~g}, 0.03 \mathrm{~mol})$, absolute methanol $(60 \mathrm{ml})$ and $64 \%$ hydrazine hydrate $(20 \mathrm{ml})$ were heated under reflux at $110^{\circ} \mathrm{C}$ for $4 \mathrm{~h}$. The dihydrazide $\mathbf{1 b}$ precipitated and was filtered off. The filtrate was evaporated to dryness to give an additional solid which was combined with the previous batch and recrystallized from water to afford light-yellowish-white solid $\mathbf{1 b}$ in $85 \%$ yield $(5.10 \mathrm{~g})$.

\section{$N^{1}, N^{4}$-Bis(4-hydroxy-3-methoxybenzylidene) terephthalohydrazide (1c; Scheme 1)}

The Schiff base was prepared by dropwise addition of a solution of 1b $(0.388 \mathrm{~g}, 0.002 \mathrm{~mol})$ in dimethylformamide (DMF; $40 \mathrm{ml})$ to a stirred solution of vanillin $(0.692 \mathrm{~g}, 0.004 \mathrm{~mol})$ in DMF $(60 \mathrm{ml})$ containing a few drops of concentrated $\mathrm{HCl}$. The reaction mixture was heated to reflux for $5 \mathrm{~h}$. A yellow precipitate was formed after cooling. Distilled water $(200 \mathrm{ml})$ was added and the mixture was kept in a refrigerator. After $8 \mathrm{~h}$, the precipitate was filtered.

Yield 85\%; m.p. > $350^{\circ} \mathrm{C}$. IR $\left(\mathrm{KBr}, \mathrm{cm}^{-1}\right)$ : 3407.28 (br), $3247.78(\mathrm{w})$, $3018.32(w), 3068.46(w), 3037.95(w), 1668.24(m), 1635.97(m)$, $1594.24(\mathrm{~m}), 1509.13(\mathrm{~m}), 1275.73$ (s). ${ }^{1} \mathrm{H}$ NMR (DMSO- $d_{6}$, $400 \mathrm{MHz}): 11.78(2 \mathrm{H}, \mathrm{s}, \mathrm{OH}), 9.56(2 \mathrm{H}, \mathrm{s}, \mathrm{NH}), 8.37\left(2 \mathrm{H}, \mathrm{s}, \mathrm{H}_{8}, \mathrm{H}_{16}\right)$, $8.03\left(4 \mathrm{H}, \mathrm{s}, \mathrm{H}_{2}, \mathrm{H}_{3}, \mathrm{H}_{5}, \mathrm{H}_{6}\right), 7.34\left(2 \mathrm{H}, \mathrm{s}, \mathrm{H}_{10}, \mathrm{H}_{22}\right), 7.12\left(2 \mathrm{H}, \mathrm{d}, J_{\mathrm{H} 14}\right.$, $\left.\mathrm{H} 13=8.0 \mathrm{~Hz}, \mathrm{H}_{14}, \mathrm{H}_{18}\right), 6.87\left(2 \mathrm{H}, \mathrm{d}, \mathrm{J}_{\mathrm{H} 13, \mathrm{H} 14}=8.0 \mathrm{~Hz}, \mathrm{H}_{13}, \mathrm{H}_{19}\right), 3.84$ $\left(6 \mathrm{H}, \mathrm{s}, \mathrm{H}_{23}, \mathrm{H}_{24}\right) .{ }^{13} \mathrm{C}$ NMR (DMSO- $\left.d_{6}\right): 162.34\left(\mathrm{C}_{7}, \mathrm{C}_{15}\right), 152.07\left(\mathrm{C}_{11}\right.$, $\left.C_{21}\right), 144.37\left(C_{12}, C_{20}\right), 140.98\left(C_{8}, C_{16}\right), 135.97\left(C_{1}, C_{4}\right), 128.89\left(C_{2}\right.$, $\left.C_{3}, C_{5}, C_{6}, C_{9}, C_{17}\right), 122.07\left(C_{14}, C_{18}\right), 116.87\left(C_{13}, C_{19}\right), 110.32\left(C_{10}\right.$, $\left.\mathrm{C}_{22}\right), 46.20\left(\mathrm{C}_{23}, \mathrm{C}_{24}\right)$. Anal. Found for $\mathrm{C}_{24} \mathrm{H}_{22} \mathrm{~N}_{4} \mathrm{O}_{6}(\%): \mathrm{C}, 62.21 ; \mathrm{H}$, 4.93; N, 12.41; O, 20.10. Calculated (\%): C, 62.30; H, 4.93; N, 12.50; O, 20.27 .

\section{Synthesis of palladium nanocomposite (2a; Scheme 2)}

Two micro-emulsion systems (I and II) were prepared for the synthesis of palladium nanocomposite using CTAB as surfactant and acetate as co-anion using the reverse micelle method. Micro-emulsion I comprised CTAB as the surfactant, $n$-butanol as the co-surfactant, isooctane as the hydrocarbon phase, distilled

$$
\underset{2}{\mathrm{Pd}(\mathrm{OAc})_{2}} \frac{\text { Micro - emulstion } 1}{\text { Micro - emulstion } 2} \mathrm{Pd} \text { Nanocomposite }
$$

Scheme 2. Reagents and conditions for the synthesis of palladium nanocomposite. 
water and $0.417 \mathrm{mmol}$ of the ligand (L). Similarly, micro-emulsion II was prepared containing the same constituents as micro-emulsion I excepting that ligand $(\mathrm{L})$ was $0.417 \mathrm{mmol}$ of $\mathrm{Pd}(\mathrm{OAc})_{2}$. The weight fractions of the various constituents utilized in these microemulsions were: $16.66 \%$ of CTAB, $17.70 \%$ of $n$-butanol, $57.4 \%$ of isooctane and $8.1 \%$ of the aqueous phase. The two microemulsions were mixed together very slowly and stirred overnight using a magnetic stirrer, as reported previously. ${ }^{[60]}$ The pale green precipitate so obtained was separated from the apolar solvent and the surfactant by centrifuging and was thoroughly washed with HPLC-grade chloroform. The compound so obtained was then air-dried and used without any further purification.

Yield $160 \mathrm{mg}$ (60\%). ${ }^{1} \mathrm{H}$ NMR (DMSO- $d_{6}, 400 \mathrm{MHz}$ ): $11.78(2 \mathrm{H}, \mathrm{s}$, $\mathrm{OH}), 9.72(2 \mathrm{H}, \mathrm{s}, \mathrm{NH}), 8.56\left(2 \mathrm{H}, \mathrm{s}, \mathrm{H}_{8}, \mathrm{H}_{16}\right), 8.03\left(4 \mathrm{H}, \mathrm{s}, \mathrm{H}_{2}, \mathrm{H}_{3}, \mathrm{H}_{5}\right.$, $\left.\mathrm{H}_{6}\right), 7.52\left(2 \mathrm{H}, \mathrm{s}, \mathrm{H}_{10}, \mathrm{H}_{22}\right), 7.40\left(2 \mathrm{H}, \mathrm{d}, J_{\mathrm{H} 14, \mathrm{H} 13}=8.0 \mathrm{~Hz}, \mathrm{H}_{14}, \mathrm{H}_{18}\right)$, $7.09\left(2 \mathrm{H}, \mathrm{d}, J_{\mathrm{H} 13, \mathrm{H} 14}=8.0 \mathrm{~Hz}, \mathrm{H}_{13}, \mathrm{H}_{19}\right), 3.95\left(6 \mathrm{H}, \mathrm{s}, \mathrm{H}_{23}, \mathrm{H}_{24}\right), 3.86$ $\left(3 \mathrm{H}, \mathrm{s}, \mathrm{CH}_{3}\right.$, acetate ion). Solid-state UV-visible: $\lambda_{\max }(\mathrm{nm}, \log 3)$ : 416.8 (1.510), 490.5 (0.536), 510.5 (0.432).

\section{General procedure for heck reaction (Scheme 3)}

To a mixture of $\mathrm{K}_{2} \mathrm{CO}_{3} \quad(138.25 \mathrm{mg} 1.0 \mathrm{mmol}$ ), palladium nanocatalyst $(6.8 \mathrm{mg}, 0.1 \mathrm{mmol})$, tetrabutylammonium bromide (TBAB; $161.18 \mathrm{mg} 0.5 \mathrm{mmol}$ ) and $\mathrm{N}$-methyl-2-pyrrolidone (NMP; $5 \mathrm{ml}$ ) was added aryl halide 4 (78 $\mathrm{mg}, 0.5 \mathrm{mmol}$ ) and allyl acetate 3 (100 mg, $1.0 \mathrm{mmol}, 2.0$ eq.) subsequently. The reaction mixture was vigorously stirred under air or nitrogen atmosphere at $120^{\circ} \mathrm{C}$ for an appropriate time (see Scheme 4) until the reaction was completed, as monitored by TLC. After cooling to room temperature and concentrating in vacuum, it was centrifuged and filtered. The precipitate was washed using dichloromethane $(3 \times 5 \mathrm{ml})$. The extracted solutions were combined and washed with water three times. The crude product was purified by chromatography on a short silica gel (eluent: petroleum ether-ethyl acetate, 20:1) to afford $80 \mathrm{mg}$ (91\%) of crude product $\mathbf{5}$. The precipitate was further washed sufficiently with distilled water and HPLC-grade chloroform then dried. The palladium nanoparticles were recovered and reused in the reaction five times, the yield of the product not obviously decreasing.

\section{Results and discussion}

\section{Characterization of palladium nanocomposite}

The structure of the palladium nanocomposite was confirmed using Fourier transform infrared (FT-IR), UV-visible, ${ }^{1} \mathrm{H}$ NMR and ${ }^{13} \mathrm{C}$ NMR spectroscopies, powder X-ray diffraction (XRD), energydispersive X-ray spectroscopy (EDX) and transmission electron microscopy (TEM). The ${ }^{1} \mathrm{H}$ NMR spectra confirm that the ligand is symmetric (Fig. 1). ${ }^{[60-63]}$ The palladium metal is capped by the ligand with acetate ion as co-anion forming a stable nanocomposite. The ${ }^{1} \mathrm{H}$ NMR spectrum of the free ligand shows signals at $11.78 \mathrm{ppm}$ for $\mathrm{OH}$ proton; while a singlet appears at $9.56 \mathrm{ppm}$ due to $\mathrm{NH}$ proton, azomethine proton as a singlet appears at $8.37 \mathrm{ppm}$ and aromatic ring proton signals appear in

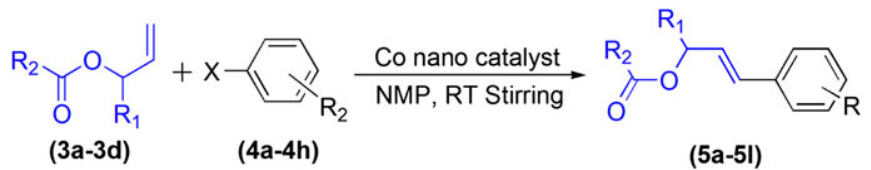

Scheme 3. Synthesis of 5 a Heck reaction product.

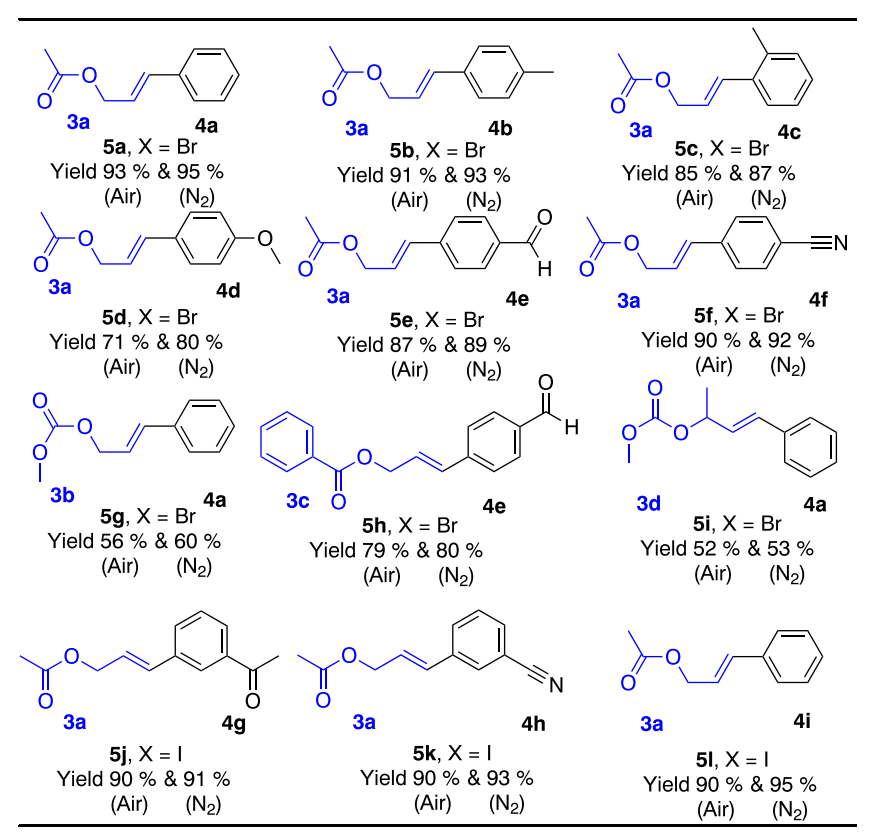

Scheme 4. Palladium nanocomposite-catalysed Heck reaction of allyl acetates 3 with various aryl halides 4. Reaction conditions: $\mathrm{K}_{2} \mathrm{CO}_{3}$ (138.25 mg, $1.0 \mathrm{mmol})$, palladium nanocatalyst $(6.8 \mathrm{mg}, 0.1 \mathrm{mmol})$, TBAB (161.18 $\mathrm{mg}, 0.5 \mathrm{mmol})$ and NMP $(2.5 \mathrm{ml})$ to which were added 3 (61 mg, $0.5 \mathrm{mmol})$ and $4\left(100 \mathrm{mg}, 1.0 \mathrm{mmol}, 2.0\right.$ eq.) at $120^{\circ} \mathrm{C}$ under nitrogen and air. The yields shown are isolated yields.

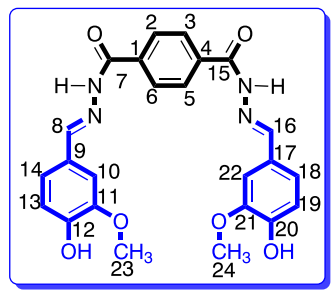

Figure 1. Structure of TPA-derived ligand 1c.

the range 8.00 to $6.85 \mathrm{ppm}$. In the ${ }^{1} \mathrm{H}$ NMR spectrum of the synthesized nanocomposite using $\mathrm{CH}_{3} \mathrm{COO}^{-}$as the co-anion, signals are observed with the loss of splitting (Fig. 2). The ${ }^{1} \mathrm{H}$ NMR signals of the palladium nanocomposite are found to be downfield shifted as compared to the free ligand. The proton of $\mathrm{NH}$ moiety appears at $9.72 \mathrm{ppm}$ instead of $9.56 \mathrm{ppm}$, azomethine proton appears at $8.56 \mathrm{ppm}$ instead of $8.37 \mathrm{ppm}$ and methyl protons are found at $3.95 \mathrm{ppm}$ compared to $3.84 \mathrm{ppm}$ for the free ligand of respective peaks with loss of splitting, while only aromatic protons show a very slight shift in position. Meanwhile NH proton signals and aromatic proton signals show downfield shifts which are indicative of paramagnetic surroundings which confirm the existence of the palladium nanocomposite. ${ }^{[60]}$

$\mathrm{LPd}(\mathrm{OAc})_{2}$ (nanocomposite with $\mathrm{OAc}$ as the co-anion) shows polydispersity. The solid-state electronic spectrum of the TPA ligand (Fig. 3) shows two strong bands in the region 176-220 nm which are assigned to the $\pi-\pi^{*}$ transition, characteristic bands of the terephthalic acid group. A broad intense $d-d$ band observed in the region of $430 \mathrm{~nm}$ is the characteristic band due to the presence of $\mathrm{Pd}(\mathrm{II})$ ion, which is coordinated to the TPA ligand. ${ }^{[64]}$ The lowenergy $d-d$ transition suggests severely square planar geometry for the palladium nanocomposite. The square planer structure of 


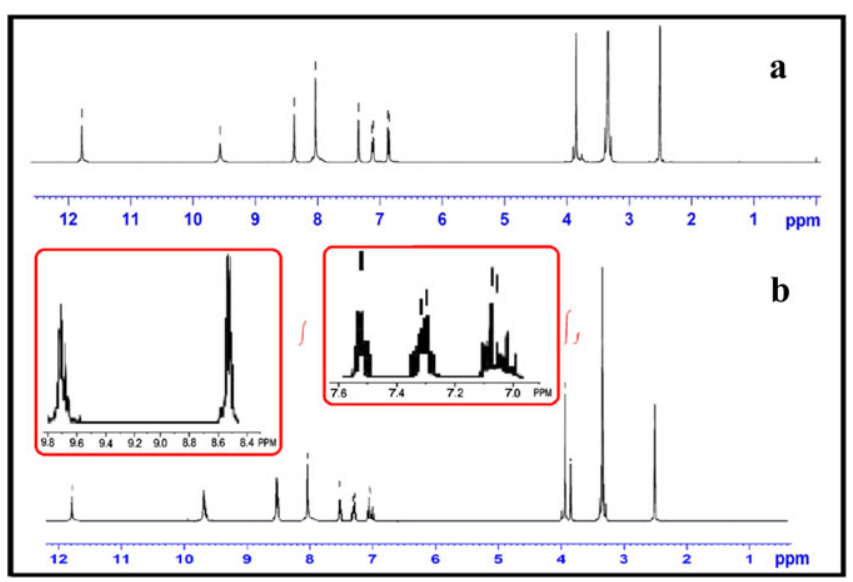

Figure 2. ${ }^{1} \mathrm{H}$ NMR spectra of (a) TPA ligand and (b) palladium nanocomposite, a comparison indicating the presence of ligand with metal.

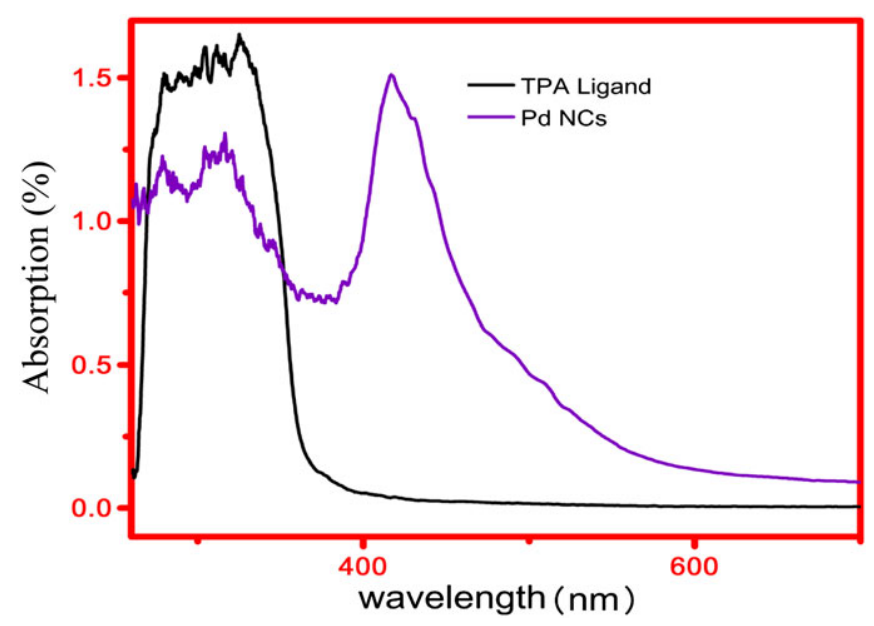

Figure 3. Solid-state electronic spectra of TPA ligand and palladium nanocomposite, a comparison indicating the presence of palladium metal.

$\mathrm{LPd}(\mathrm{OAc})_{2}$ capped by TPA group could provide suitable anchoring sites on the nano-surface. ${ }^{[66]}$

The FT-IR spectrum of the ligand shows characteristic bands at 1668 and $1635 \mathrm{~cm}^{-1}$ (Fig. 4). These are assigned to amide $\mathrm{C}=\mathrm{O}$ stretching and $\mathrm{C}=\mathrm{N}$ stretching frequencies, respectively. Strong and sharp bands at 1275 and $3407 \mathrm{~cm}^{-1}$ are assigned to vanillin

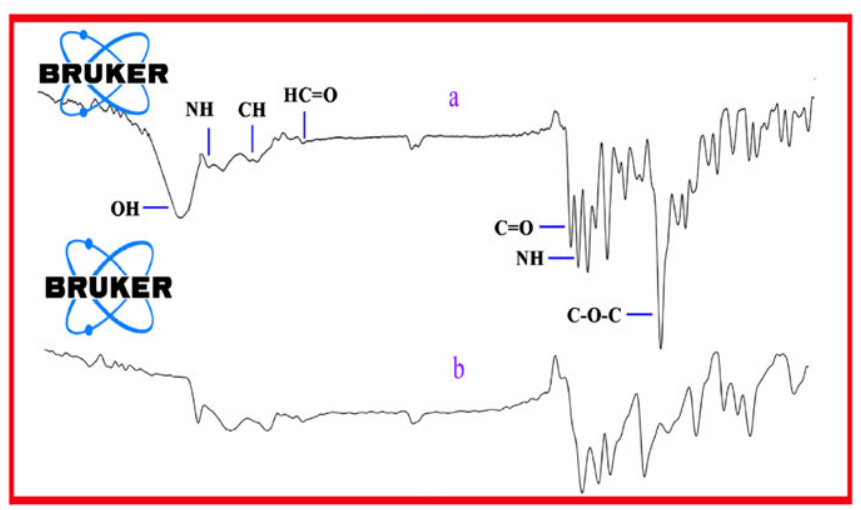

Figure 4. FT-IR Spectrum of TPA ligand and palladium nano-composite.
$\mathrm{C}-\mathrm{O}-\mathrm{C}$ stretching and presence of $\mathrm{OH}$ group in the molecule and a band at $3247 \mathrm{~cm}^{-1}$ is assigned to an $\mathrm{N}-\mathrm{H}$ stretching mode. In the FT-IR spectrum of the palladium nanocomposite, mainly the amide linkage $\mathrm{C}=\mathrm{O}$ and $\mathrm{C}=\mathrm{N}$ bands are shifted to 1610 and $1537 \mathrm{~cm}^{-1}$, respectively. It is interesting to note that in the nanocomposite spectrum, the $\mathrm{OH}$ and $\mathrm{C}-\mathrm{O}-\mathrm{C}$ bands are weak and shifted to higher energy. The presence of acetate anions in the palladium nanocomposite is confirmed by the appearance of a strong band at $1340 \mathrm{~cm}^{-1}\left(\mathrm{COO}^{-}\right)$. Thus the FT-IR data clearly indicate that the palladium ions are completely bound to the TPA ligand in the nanocomposite. ${ }^{[64]}$

The formation of palladium nanoparticles is confirmed from the powder XRD pattern (Fig. 5(c)). All peaks of palladium nanocomposite are observed in the diffractogram in the $2 \theta$ range $40-90^{\circ}$, indicating the crystalline nature of palladium nanoparticles. The X-ray reflections are indexed to the face-centred cubic structure of the palladium nanocomposite and the diffraction peaks observed at $2 \theta$ values of $40^{\circ}, 46^{\circ}, 68^{\circ}, 82^{\circ}$ and $87^{\circ}$, respectively, represent the (111), (200), (220), (311) and (222) Bragg reflections matching with the literature JCPDS standard card (no. 05-0681) and confirming the formation of palladium nanoparticles with hollow shape facecentred cubic crystal structure, which is also consistent with earlier reports. ${ }^{[65-67]}$

In order to further characterize the samples, EDX data were recorded (Fig. 5(d)). The results show that palladium metal is covered with organic species and also reveal that the hollow spheres of the palladium nanocomposite are composed of minor amounts of carbon, oxygen and bromine which came from the organic ligand and CTAB.

Figures 5(a) and (b) show typical TEM images of the palladium nanocomposite confirming that the palladium nanoparticles have hollow spherical structure. As can be seen from the images, the pale coloured regions in the central parts, in contrast to dark spot, imply a spherical structure. The unchanged contrast difference between the centre and edge in the TEM image of one sphere obtained when the sample grid is rotated by different degrees further proves the spherical structure. The average diameter of the spherical structure is about $5 \mathrm{~nm}$. To the best of our knowledge, this is a novel synthesis of a TPA ligand-stabilized palladium nanocomposite using the reverse micelle method. The overall result for the palladium

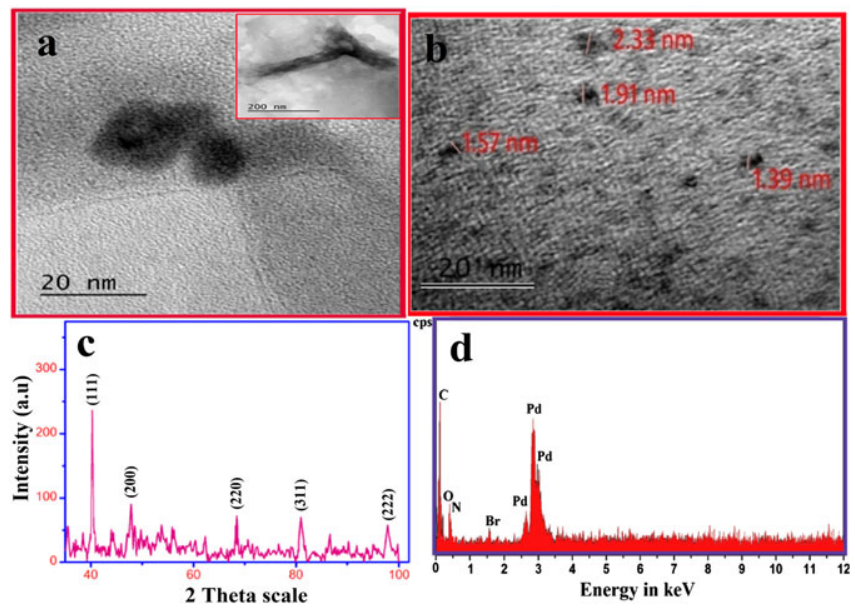

Figure 5. (a) High-magnification and low-magnification (inset) TEM image, (b) High-magnification of palladium nano-composite with particle size, (c) PXRD spectrum of palladium nano-composite and (d) EDX spectrum of palladium nano-composite. 
nanocomposite shows that the TPA ligand serves as a good capping agent and provides good stability at nano-sized palladium metal atom.

\section{Heck coupling reaction of aryl halide and allyl acetate}

Another important aspect of our research is the application of the palladium nanocomposite for the Heck reaction. The palladium nanocomposite is less soluble in most common organic solvents, but it is partially soluble in DMF and dimethylsulfoxide (DMSO) and hence it shows good anchoring of heterogeneity. This heterogeneity of the palladium nanocomposite is very helpful in terms of recovery of the catalyst without loss of its activity even after five recycles.

The palladium-catalysed Heck-type reaction of allyl acetate with aryl halides in the presence of a base is represented in Scheme 3. A set of experiments were carried out using allyl acetate $\mathbf{3} \mathbf{a}$ and aryl bromide $\mathbf{4 a}$ as model substrates. We tested various reaction conditions for the arylation of allyl acetate. The results are summarized in Tables 1-3. Firstly, these two coupling partners were reacted in NMP at $120^{\circ} \mathrm{C}$, under air and nitrogen atmosphere condition in the absence of palladium nanocomposite: no arylation product $\mathbf{5 a}$ is obtained. When $0.5 \mathrm{mmol}$ of palladium nanocomposite is employed only $50 \%$ of $\mathbf{5 a}$ is obtained (Table 3 , entry 5). We find the arylation product $\mathbf{5 a}$ in very trace amount when methanol is used as solvent, so we replaced methanol with NMP which, gratifyingly, results in significant increase of the yield (Table 1, entry 1). The screening of solvents with palladium nanocomposite reveals that the yield of $\mathbf{5 a}$ is much higher in NMP than in $\mathrm{MeOH}, \mathrm{EtOH}$, $\mathrm{AcOH}$ and dioxane. After screening of various bases it is found that $\mathrm{K}_{2} \mathrm{CO}_{3}$ is the most effective and $\mathrm{CH}_{3} \mathrm{COONa}$ is a competitively good base compared to other bases, such as $\mathrm{NEt}_{3}, \mathrm{NaHCO}_{3}$ and $\mathrm{KOH}$ (Table 2, entries 1-4). Further studies were carried out to determine the influence of catalyst loading on product yield. A loading of $0.5 \mathrm{mmol} \mathrm{I}^{-1}$ of catalyst leads to a yield of below $50 \%$; on the other hand, a very small quantity, say $0.001 \mathrm{mmol}^{-1}$, produces a moderately good yield. Therefore, here we conclude that $0.01 \mathrm{mmol} \mathrm{I}^{-1}$ loading of catalyst is very effective for obtaining higher yield

\begin{tabular}{|c|c|c|}
\hline Entry & Solvent & Yield (\%) ${ }^{\mathrm{b}}$ \\
\hline 1 & $\mathrm{NMP}^{c}$ & 93,95 \\
\hline 2 & $\mathrm{MeCN}^{c}$ & 87,91 \\
\hline 3 & Acetone & 83 \\
\hline 4 & $\mathrm{MeOH}$ & Trace \\
\hline 5 & Ethanol & $>20$ \\
\hline 6 & Dioxane & $>20$ \\
\hline 7 & Toluene & 65 \\
\hline 8 & $\mathrm{MeOH}-\mathrm{H}_{2} \mathrm{O}(6: 4)^{\mathrm{c}}$ & $60,>30$ \\
\hline 9 & $\mathrm{EtOH}-\mathrm{H}_{2} \mathrm{O}(6: 4)^{\mathrm{c}}$ & $78,>50$ \\
\hline 10 & DMF & 87 \\
\hline 11 & DMSO & 85 \\
\hline \multicolumn{3}{|c|}{$\begin{array}{l}\text { a'Reaction conditions: } \mathrm{K}_{2} \mathrm{CO}_{3}(138.25 \mathrm{mg} 1.0 \mathrm{mmol}, 2.0 \text { eq.), palladium } \\
\text { nanocatalyst ( } 6.8 \mathrm{mg}, 0.1 \mathrm{mmol}), \mathrm{TBAB}(161.18 \mathrm{mg}, 0.5 \mathrm{mmol}) \text { and } \\
\text { solvent }(2.5 \mathrm{ml}) \text { to which were added bromobenzene } 4 \mathrm{a}(61 \mathrm{mg} \text {, } \\
0.5 \mathrm{mmol}) \text { and allyl acetate } 3 \mathrm{a}\left(100 \mathrm{mg}, 1.0 \mathrm{mmol}, 2.0 \text { eq.) at } 120^{\circ} \mathrm{C}\right. \\
\text { under nitrogen. } \\
\text { blsolated yield. } \\
\text { 'Under nitrogen and air. }\end{array}$} \\
\hline
\end{tabular}

Table 2. Optimization of base with selected solvent ${ }^{\mathrm{a}}$

\begin{tabular}{lllc} 
Entry & Solvent & \multicolumn{1}{c}{ Base } & Yield (\%) ${ }^{\mathrm{b}}$ \\
\hline 1 & $\mathrm{NMP}$ & $\mathrm{K}_{2} \mathrm{CO}_{3}{ }^{\mathrm{c}}$ & 90,70 \\
2 & $\mathrm{NMP}$ & $\mathrm{CH}_{3} \mathrm{COONa}^{\mathrm{c}}$ & 88,63 \\
3 & $\mathrm{NMP}$ & $\mathrm{NEt}_{3}{ }^{\mathrm{c}}$ & $>20$ \\
4 & $\mathrm{NMP}$ & $\mathrm{NaHCO}_{3}{ }^{\mathrm{c}}$ & 64,60 \\
5 & $\mathrm{NMP}$ & $\mathrm{KOH}^{\mathrm{c}}$ & $70,>30$ \\
6 & $\mathrm{NMP}$ & $\mathrm{NaOH}^{\mathrm{c}}$ & $65,>30$ \\
7 & $\mathrm{MeCN}$ & $\mathrm{K}_{2} \mathrm{CO}_{3}$ & $>20$ \\
8 & Acetone & $\mathrm{K}_{2} \mathrm{CO}_{3}$ & 60 \\
9 & MeCN & $\mathrm{CH}_{3} \mathrm{COONa}$ & 78 \\
10 & Acetone & $\mathrm{CH}_{3} \mathrm{COONa}$ & 66 \\
\hline
\end{tabular}

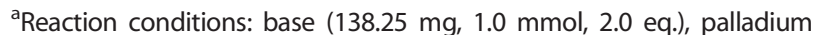
nanocatalyst $(6.8 \mathrm{mg}, 0.1 \mathrm{mmol})$, TBAB $(161.18 \mathrm{mg}, 0.5 \mathrm{mmol})$ and solvent $(2.5 \mathrm{ml})$ to which were added bromobenzene $4 \mathrm{a}(61 \mathrm{mg}$, $0.5 \mathrm{mmol}$ ) and allyl acetate $3 \mathrm{a}\left(100 \mathrm{mg}, 1.0 \mathrm{mmol}, 2.0\right.$ eq.) at $120^{\circ} \mathrm{C}$ under nitrogen.

b Isolated yield.

'Under nitrogen and air.

Table 3. Optimization of catalyst loading under model reaction conditions $^{\mathrm{a}}$

\begin{tabular}{|ccc|}
\hline Entry & Catalyst $\left(\mathrm{mol} \mathrm{I}^{-1}\right)$ & Yield (\%) \\
\hline 1 & 0.001 & 80 \\
2 & 0.01 & 94 \\
3 & 0.1 & 80 \\
4 & 0.05 & 70 \\
5 & 0.5 & $>50$ \\
\hline
\end{tabular}

${ }^{\mathrm{a}}$ Reaction conditions: $\mathrm{K}_{2} \mathrm{CO}_{3}(138.25 \mathrm{mg}, 1.0 \mathrm{mmol}, 2.0 \mathrm{eq}$.), palladium nanocatalyst, TBAB $(161.18 \mathrm{mg}, 0.5 \mathrm{mmol})$ and NMP $(2.5 \mathrm{ml})$ to which were added bromobenzene $4 \mathbf{a}(61 \mathrm{mg}, 0.5 \mathrm{mmol})$ and allyl acetate $\mathbf{3 a}$ (100 mg, $1.0 \mathrm{mmol}, 2.0$ eq.) at $120^{\circ} \mathrm{C}$ in about $8 \mathrm{~h}$ under nitrogen.

(Table 3, entry 2). Typically higher yield is observed under nitrogen atmosphere than with air which leads to a variation of 10 to $20 \%$ yield in most of the reactions (Scheme 4). With the optimized reaction conditions in hand, we probed the scope of allyl acetate reaction with various aryl halides employing $2 \mathrm{~mol} \%$ palladium nanocomposite in NMP at $120^{\circ} \mathrm{C}$ under nitrogen atmosphere. The results are summarized in Scheme 4 (considering only weight of TPA ligand and weight of palladium metal).

The reaction scope was subsequently explored using various allyl acetates (3a-3d) with appropriate aryl halides (4a-4 h). Excellent isolated yield of arylation product $(\mathbf{5 a}-\mathbf{5} \mathbf{~ I})$ is obtained with $2 \mathrm{~mol} \%$ of palladium nanocomposite in 5-8 $\mathrm{h}$. Aryl halides with electron-withdrawing substituents work equally as well as those with electron-donating substituents, giving arylation products like $\mathbf{5 a}, \mathbf{5 b}$ and $\mathbf{5 f}$ (Scheme 4). In particular, $p$-methylbromobenzene $\mathbf{4 b}$ and 4-bromobenzonitrile $\mathbf{4 f}$ with allyl acetate result in higher yield of products $\mathbf{5 b}$ and $\mathbf{5 f}$, respectively (Scheme 4). The reaction of $o$-methylbromobenzene $\mathbf{4} \mathbf{c}$ with terminal alkene gives smaller yield under optimized conditions; the reason for this is due to steric factors restricting the reaction (Scheme 4). The reaction appears sluggish with aryl chlorides, while aryl iodides are more reactive than the corresponding aryl bromides in this palladiumcatalysed reaction. ${ }^{[10,11]}$ The reductive couplings with aryl iodides are complete in $6 \mathrm{~h}$ and produced higher yields with just $2 \mathrm{~mol} \%$ 
of the palladium nanocomposite catalyst (last row of Scheme 4). Thus, $m$-corbanyliodobenzene $\mathbf{4} \mathbf{g}$ reacts with allyl acetate $\mathbf{3 a}$ forming $\mathbf{5 j}$ with $91 \%$ yield. Similarly, 3 -iodobenzonitrile $\mathbf{4} \mathbf{h}$ reacts with allyl acetate $\mathbf{3 a}$ to afford the substituted aryl product $\mathbf{5} \mathbf{k}$ in excellent yield (Scheme 4). Also, the non-substituted aryl iodide gives highest $95 \%$ yield under similar conditions. Excitingly, extremely efficient reactions are observed in the case of $\mathbf{4 b} \mathbf{b} \mathbf{4 e}$ and $\mathbf{4 f}$, affording their corresponding products $\mathbf{5 b}$, $\mathbf{5 e}$ and $\mathbf{5} \mathbf{f}$ in high yield after 6,5 and 5 h respectively $(93,92$ and $89 \%$ yield; Scheme 4).

The present strategy can be further extended to other substituted allyl acetates with corresponding aryl halides under similar catalytic conditions leading to unusually less product yield. Methylprop-2-en-1-yl carbonate $\mathbf{3 b}$ and but-3-en-2-yl acetate $\mathbf{3 d}$ with aryl bromide $\mathbf{4 a}$ offer 60 and $53 \%$ yield, respectively (allyl acetate substituted entries in Scheme 4). The remaining percentage is the formation of side product which was confirmed by TLC but could not be isolated and characterized. The result indicates that any substitution at terminal alkene affects the product yield significantly (Schemes 5 and 6). From the overall results it is concluded that the palladium nanocomposite is an efficient catalyst for Heck coupling reactions and also shows wide range of functional group tolerance.

\section{Efficiency and excellence in catalyst recovery}

The crucial part of the coupling reaction is recovery of the palladium catalyst at the end of the reaction. Here we report the extremely efficient recovery of the palladium nanocomposite, which was employed in the reaction of bromobenzene and allyl acetate as coupling partners under the optimized reaction conditions. The reactions were stopped by centrifugation (4000 rpm, $10 \mathrm{~min}$ ), the precipitate was collected and redispersed in dichloromethane, three times extracted solutions were combined with supernatant liquid and washed with doubly distilled water three times, and 95\% yield was obtained in the first cycle, The recycled catalyst was used for subsequent runs of the model reaction under the same conditions, giving 94, 93, 92 and $90 \%$ of isolated yields for the second, third, fourth and fifth runs, respectively. It is clear from the FT-IR spectrum (Fig. 6) of the palladium nanocomposite after five cycles of Heck reaction that the molecular ligand is strongly

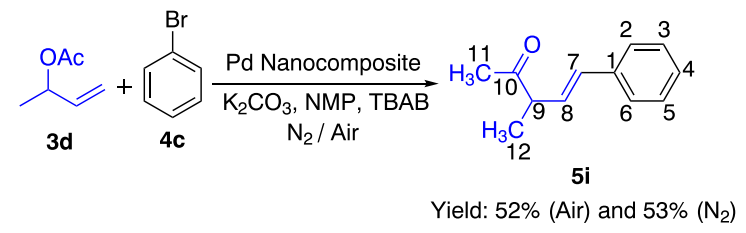

Scheme 5. Phenylation of substituted allyl acetate having low yield of product.

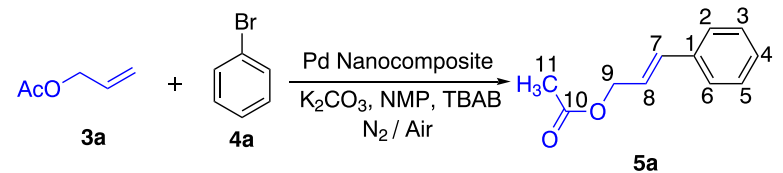

Yield: $93 \%$ (Air) and $95 \%\left(\mathrm{~N}_{2}\right)$

Scheme 6. Phenylation of without substituted allyl acetate having high yield of product.

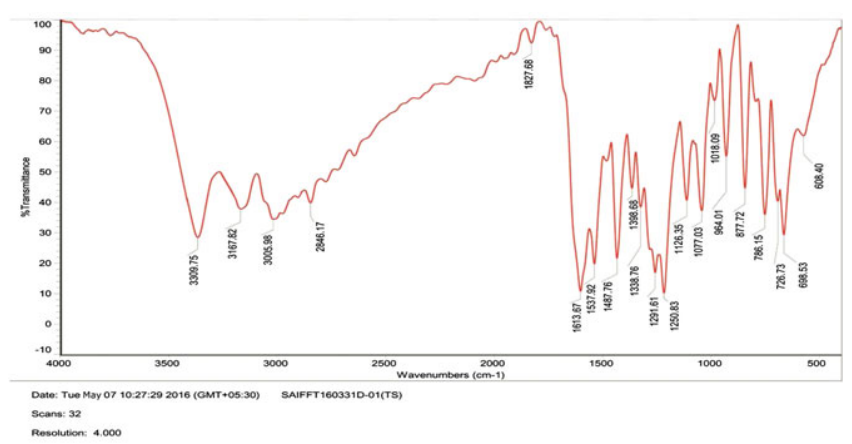

Figure 6. FT-IR Spectrum of palladium nano-composite after catalyzing fifth cycle of Heck reaction.

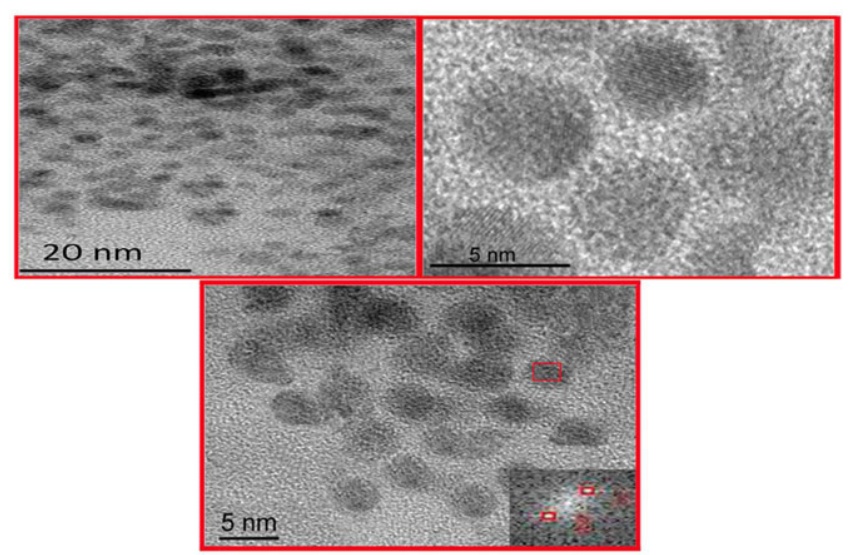

Figure 7. High-resolution TEM images of palladium nanocomposite after catalysing the Heck coupling reaction for up to five cycles.

bound to the palladium metal atom even after the catalytic reaction. Figure 7 shows typical TEM images of the palladium nanocomposite structure, after catalysing five cycles of the Heck reaction. The images show that a little swelling or increase in size of nanoparticles due to agglomeration or surface coating by other particles leads to the decrease of the catalytic activity markedly after the fifth cycle.

\section{Conclusions}

We report a new type of palladium nanocomposite based on TPA ligand, which exhibits excellent catalytic efficiency towards Heck reactions. It is demonstrated that the TPA ligand is capable of completely wrapping a palladium metal nanoparticle as well as serving as a stabilizer for keeping the palladium nanocomposite from particle coalescence via a weak coordination bond between ligand and metal nanoparticle. Such a relatively weak coordination bond facilitates the ligand exchange reactions and maintains the active sites exposed on the surface, hence showing high catalytic activity.

\section{Acknowledgements}

We are grateful to UGC, New Delhi for financial assistance and STIC (Sophisticated Test and Instrumentation Centre), Cochin for spectral studies. 


\section{References}

[1] E. Ramirez, S. Jansat, K. Philippot, P. Lecante, M. Gomez, A. M. Masdeu-Bulto, B. Chaudret, J. Organomet. Chem. 2004, 689, 4601.

[2] F. Dassenoy, K. Philippot, T. Ould-Ely, C. Amiens, P. Lecante, E. Snoeck, A. Mosset, M. J. Casanove, B. Chaudret, New J. Chem. 1998, 22, 703.

[3] S. Gomez, L. Erades, K. Philippot, B. Chaudret, V. Colliere, O. Balmes, J. O. Bovin, Chem. Commun. 2001, 1474.

[4] C. Pan, K. Pelzer, K. Philippot, B. Chaudret, F. Dassenoy, P. Lecante, M. J. Casanove, J. Am. Chem. Soc. 2001, 123, 7584.

[5] A. Rodriguez, C. Amiens, B. Chaudret, M. J. Casanove, P. Lecante, J. S. Bradley, Chem. Mater. 1996, 8, 1978.

[6] B. J. Hornstein, J. D. Aiken, III, R. G. Finke, Inorg. Chem. 2002, 41, 1625.

[7] J. A. Widegren, M. A. Bennett, R. G. Finke, J. Am. Chem. Soc. 2003, 125, 10301.

[8] J. A. Widegren, R. G. Finke, J. Mol. Catal. A 2003, 198, 317.

[9] S. U. Son, Y. Jang, K. Y. Yoon, E. Kang, T. Hyeon, Nano Lett. 2004, 4, 1147.

[10] G. Schmid, V. Maihack, F. Lantermann, S. Peschel, J. Chem. Soc. Dalton Trans. 1996, 589.

[11] G. Schmid, M. Baumle, M. Geerkens, I. Heim, C. Osemann, T. Sawitowski, Chem. Soc. Rev. 1999, 28, 179.

[12] W. Shenton, D. Pum, U. B. Sleytr, S. Mann, Nature 1997, 389, 585.

[13] T. Cassagneau, T. E. Mallouk, J. H. Fendler, J. Am. Chem. Soc. 1998, 120, 7848.

[14] K. Soulantika, A. Maisonnat, B. Chaudret, F. Senocq, M. C. Fromen, M. J. Casanove, B. Chaudret, Angew. Chem. 2001, 113, 3071.

[15] J. Huang, T. Jiang, B. Han, H. Gao, Y. Chang, G. Zhao, W. Wu, Chem. Commun. 2003, 1654.

[16] T. M. Gall, A. Birkner, G. Dyker, J. Organomet. Chem. 2008, 693, 1.

[17] R. Narayanan, M. A. El-Sayed, J. Am. Chem. Soc. 2003, 125, 8340.

[18] A. M. Doyle, S. K. Shaikhutdinov, S. D. Jackson, H.-J. Freund, Angew. Chem. Int. Ed. 2003, 42, 5240.

[19] M. Singla, P. Mathur, M. Gupta, M. S. Hundal, Transit. Met. Chem. 2008, 33, 175.

[20] T. Mizoroki, K. Mori, A. Ozaki, Bull. Chem. Soc. Jpn. 1971, 44, 581.

[21] R. F. Heck, J. P. Nolley, J. Org. Chem. 1972, 37, 2320.

[22] R. F. Heck, Org. React. 1982, 27, 345.

[23] M. Shibasaki, C. D. J. Boden, A. Kojima, Tetrahedron 1997, 53, 7371.

[24] I. P. Beletskaya, A. V. Cheprakov, Chem. Rev. 2000, 100, 3009.

[25] N. J. Whitcombe, K. K. Hii, S. E. Gibson, Tetrahedron 2001, 57, 7449.

[26] A. F. Littke, G. C. Fu, Angew. Chem., Int. Ed. 2002, 41, 4176.

[27] F. Alonso, I. P. Beletskaya, M. Yus, Tetrahedron 2005, 61, 11771.

[28] A. D. Meijere, F. E. Meyer, Angew. Chem. Int. Ed. Engl. 1994, 33, 2379.

[29] S. E. Gibson, R. J. Middleton, Contemp. Org. Synth. 1996, 3, 447.

[30] A. B. Dounay, L. E. Overman, Chem. Rev. 2003, 103, 2945.

[31] V. Farina, Adv. Synth. Catal. 2004, 346, 1553.

[32] M. T. Reetz, E. Westermann, R. Lohmer, G. Lohmer, Tetrahedron Lett. 1998, 39, 8449 .

[33] M. T. Reetz, G. Lohmer, R. Schwickardi, Angew. Chem. Int. Ed. 1998, 37, 481.

[34] A. H. M. de Vries, J. M. C. A. Mulders, J. H. M. Mommers, H. J. W. Henderickx, G. J. de Vries, Org. Lett. 2003, 5, 3285.

[35] N. E. Leadbeater, Chem. Commun. 2005, 2881.

[36] G. D. Frey, W. A. Herrmann, J. Organomet. Chem. 2005, 690, 5876.
[37] G. D. Frey, J. Schutz, E. Herdtweek, W. A. Herrmann, Organometallics 2005, 24, 4416.

[38] C. Najera, L. Botella, Tetrahedron 2005, 61, 9688.

[39] C. M. Frech, L. J. W. Shimon, D. Milstein, Angew. Chem. Int. Ed. 2005, 44, 1709.

[40] A. F. Littke, G. C. Fu, J. Org. Chem. 1999, 64, 10.

[41] K. Selvakumar, A. Zapf, M. Beller, Org. Lett. 2002, 4, 3031

[42] D. Gelman, S. L. Buchwald, Angew. Chem. Int. Ed. 2003, 42, 5993.

[43] Y. Lunxiang, J. Liebscher, Chem. Rev. 2007, 107, 133.

[44] M. Islam, P. Mondal, K. Tuhian, A. S. Roy, J. Braz. Chem. Soc. 2011, 22, 319.

[45] H. Firouzabadi, N. Iranpoor, A. Ghaderi, M. Ghavami, S. J. Hoseini, Bull. Chem. Soc. Jpn. 2011, 84, 100.

[46] S. Jana, S. Haldar, S. Koner, Tetrahedron Lett. 2009, 50, 4820.

[47] S. Ungureanu, H. Deleuze, O. Babot, M. F. Achard, C. Sanchez, M. I. Popa, R. Backov, Appl. Catal. A 2010, 390, 51.

[48] K. Okumura, T. Tomiyama, S. Okuda, H. Yoshida, M. Niwa, J. Catal. 2010, 273, 156.

[49] P. P. Zhang, X. X. Zhang, H. X. Sun, R. H. Liu, B. Wang, Y. H. Lin, Tetrahedron Lett. 2009, 50, 4455.

[50] G. M. Scheuermann, L. Rumi, P. Steurer, W. Bannwarth, R. Mulhaupt, J. Am. Chem. Soc. 2009, 131, 8262.

[51] B. J. Gallon, R. W. Kojima, R. B. Kaner, P. L. Diaconescu, Angew. Chem. Int. Ed. 2007, 46, 7251.

[52] F. X. Llabrés i Xamena, A. Abad, A. Corma, H. Garcia, J. Catal. 2007, 250, 294.

[53] D. Saha, R. Sen, T. Maity, S. Koner, Langmuir 2013, 29, 3140.

[54] Y. Xu, Z. Zhang, J. Zheng, Q. Du, Y. Li, Appl. Organometal. Chem. 2013, $27,13$.

[55] A. L. Isfahani, I. Mohammadpoor-Baltork, V. Mirkhani, A. R. Khosropour, M. Moghadam, S. Tangestaninejad, R. Kia, Adv. Synth. Catal. 2013, 355, 957.

[56] V. W. Faria, D. G. M. Oliveira, M. H. S. Kurz, F. F. Goncalves, C. W. Scheeren, G. R. Rosa, RSC Adv. 2014, 4, 13446.

[57] E. Hariprasad, T. P. Radhakrishnan, ACS Catal. 2012, 2, 1179.

[58] M. Coa, Y. Wei, S. Gao, R. Cao, Catal. Sci. Technol. 2012, 2, 156.

[59] C. W. Robert, Handbook of Chemistry and Physics, 63rd ed, CRC Press, Boca Raton, FL, 1982-1983, p. C-529.

[60] M. Singla, S. C. Mohapatra, S. Ahmad, Mater. Chem. Phys. 2012, 137, 118.

[61] L. Po-Heng, K. Ilia, J. B. Tara, M. Muralee, Dalton Trans. 2012, 41, 13649.

[62] G. Kumar, S. Devi, R. Johari, D. Kumar, Eur. J. Med. Chem. 2012, 52, 269.

[63] H. H. Monfared, N. Asghari-Lalami, A. Pazio, K. Wozniak, C. Janiak, Inorg. Chim. Acta 2013, 406, 241.

[64] D. D. Kragten, R. A. van Santen, Inorg. Chem. 1999, 38, 331.

[65] A. Bankar, B. Joshi, A. R. Kumar, S. Zinjarde, Mater. Lett. 2010, 64, 1951.

[66] X. Yang, Q. Li, H. Wang, J. Huang, L. Lin, W. Wang, D. Sun. J. Nanopart. Res. 2010, 12, 1589.

[67] M. Sathishkumar, K. Sneha, Y. S. Yun, Int. J. Mater. Sci. 2009, 4, 11.

\section{Supporting Information}

Additional supporting information may be found in the online version of this article at the publisher's web site. 